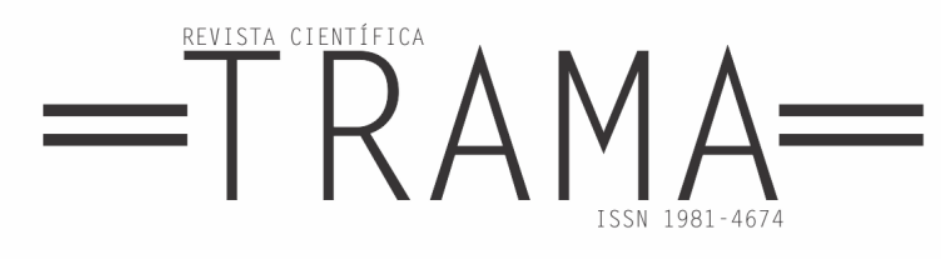

\title{
Formação de tradutores e intérpretes de LIBRAS/LÍNGUA PORTUGUESA VIA EXTENSÃO UNIVERSITÁRIA NO SEMIÁRIDO BAIANO
}

\author{
Isaac Figueiredo de FREITAS ${ }^{1}$
}

Resumo: Este artigo objetiva descrever e analisar uma experiência de formação de Tradutores e Intérpretes de Libras/Lingua Portuguesa, em nível médio, via extensão universitária, ofertada no semiárido baiano. Resultado de uma pesquisa, predominantemente, de campo, que teve como lócus o próprio espaço de formação onde o pesquisador esteve inserido atuando como professor formador e pesquisador, este trabalho trata-se de um estudo com características de uma pesquisa-ação. Os dados que fazem parte do escopo de análise deste artigo - textos escritos em Língua Portuguesa e vídeos produzidos em Libras foram cedidos por discentes na condição de colaboradores participantes. Os relatos tecidos no corpo deste artigo não visam apresentar um modelo ideal de formação, senão incitar o aprofundamento das discussões teóricas em torno da extensão universitária como modalidade de formação profissional de tradutores e intérpretes Libras/Língua Portuguesa, em nível médio.

Palavras-chave: Estudos da tradução, Formação de tradutores e intérpretes, Extensão universitária, Semiárido baiano.

\begin{abstract}
This article aims to describe and analyze a training experience for translators and interpreters of the Brazilian Sign Language (Libras) at an intermediate level, offered through university extension in the Bahian semi-arid region. It is predominantly the result of field research at the location where the researcher was placed to act as a training teacher and researcher. Thus, the study has characteristics of action research. Data analyzed and included in the scope of this article - texts written in Portuguese and videos produced in Libras - were provided by students as collaborating participants. Statements made within this article do not aim to present an ideal training model, but to incite deeper theoretical discussions around university extension as a way of training professional translators and interpreters of the Libras at an intermediate level.
\end{abstract}

Keywords: Translation studies, Training of translators and interpreters, University extension, Bahian semi-arid region.

Recebido em 04-11-2017 Aceito em 14-06-2018

\footnotetext{
${ }^{1}$ Professor de Libras, em cargo efetivo, lotado no Colegiado de Ciências da Natureza da Universidade Federal do Vale do São Francisco (UNIVASF), campus Sr. do Bonfim. Doutorando em Linguística pela Universidade Federal de Santa Catarina (UFSC) sob a orientação da Prof ${ }^{a}$ Dr $^{a}$ Marianne Rossi Stumpf. E-mail: isaacfreitas123@hotmail.com
} 


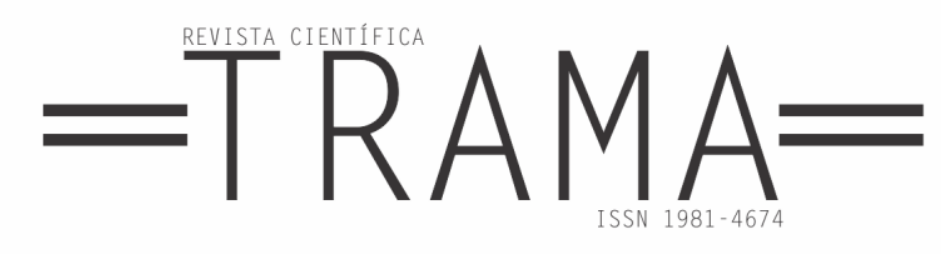

[...] que a "extensão" deixe de ser a quase irmã caçula e pobre da "trindade universitária", e venha a ocupar o lugar que uma universidade, de fato vocacionada a ser comunitária, democrática e popular, deveria assumir. (BRANDÃO, 2016, p. 13,14)

\section{INTRODUÇ̃̃o}

O presente artigo objetiva descrever e analisar uma experiência de formação de Tradutores e Intérpretes de Libras/Língua Portuguesa (TILSP), em nível médio, via extensão universitária, ofertada no semiárido baiano. Resultado de uma pesquisa de campo, sendo o lócus de intervenção e geração de dados o próprio espaço de formação onde o pesquisador esteve inserido nas condições de professor formador e pesquisador, este estudo caracteriza-se como uma pesquisa-ação.

A porção do semiárido baiano recortada para este estudo é o Território do Piemonte Norte do Itapicuru que abrange nove municípios do interior do estado da Bahia, a saber: Andorinha, Antônio Gonçalves, Campo Formoso, Caldeirão Grande, Filadélfia, Jaguarari, Pindobaçu, Ponto Novo e Senhor do Bonfim. A formação ocorreu entre outubro de 2015 e janeiro de 2017 no campus da Universidade Federal do Vale do São Francisco (Univasf) situado na cidade de Senhor do Bonfim-BA.

Figura 1 - Mapa territorial do Piemonte Norte do Itapicuru-BA

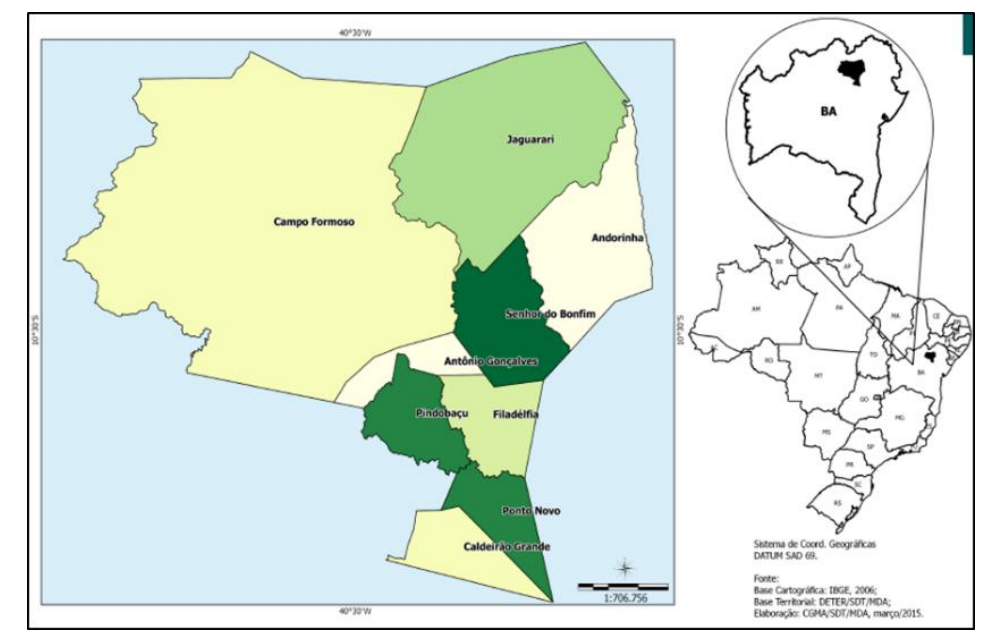

Fonte: Adaptado de Brasil (2015, p. 1)

Pesquisas situadas (FREITA, I. 2014; FREITAS. E, 2014) indicaram que a quantidade de intérpretes com formação, ou seja, com bacharelado em Letras Libras ou com certificado de proficiência em tradução e interpretação da Libras/Português/Libras, atuantes no Território do Piemonte Norte do Itapicuru, era insuficiente para atender à demanda regional. Recorrendo aos dados

\footnotetext{
${ }^{2}$ Os relatórios técnicos de todas as edições do ProLibras podem ser consultados acessando o site: 〈www.prolibras.ufsc.br〉.

3 Incluindo-se os dados da sétima edição do ProLibras à pesquisa de Freitas, E. (2014), chega-se à seguinte sinópse: das sete edições do ProLibras, o estado da Bahia obteve 151
}

dos relatórios técnicos ${ }^{2}$ das seis edições do Exame Nacional de Proficiência em Libras (ProLibras), Freitas, E. (2014) apontou, em seu estudo, que de um total de 121 pessoas certificadas para atuarem como TILSP na Bahia, apenas 7 estavam em atuação no Território do Piemonte Norte do Itapicuru. ${ }^{3}$

Estudo conduzido por Freitas, I. (2014), no mesmo território, com intérpretes

participantes aprovados e certificados para atuarem como tradutores e intérpretes de Libras/Língua Portuguesa. Desse total, 8 residiam no Território do Piemonte Norte do Itapicuru. Atualmente, porém, apenas 3, dentre os oito profissionais certificados, continuam fixados nesse território. 


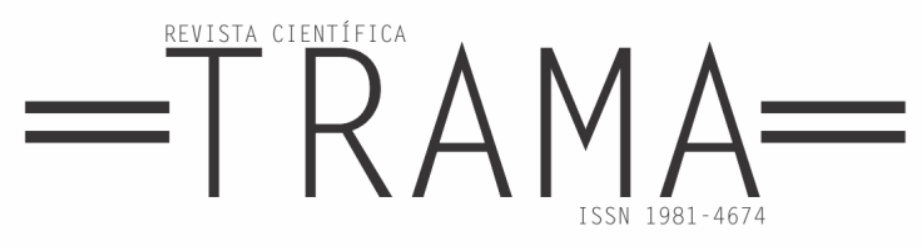

inseridos no campo educacional, constatou que alguns desses intérpretes atuavam de forma empírica, sem nenhuma formação teórica específica. A pesquisa evidenciou "que embora todos os pesquisados [fossem] fluentes nas Línguas que [interpretavam] Língua Portuguesa/LIBRAS [demonstravam] pouco rigor técnico nas diversas situações vivenciadas em sala de aula" (FREITAS, I. 2014, p. 27). Foi esse cenário de escassez profissional e ausência de espaços formais para a formação de TILSP que motivou a oferta de um curso de formação via extensão universitária.

A descrição e análise desse curso de formação para TILSP encontra-se explicitada nas seções seguintes deste trabalho científico. A próxima seção apresenta as bases legais que amparam a proposta de formação de TILSP, em nível médio, na modalidade da extensão universitária e discute as dificuldades e controvérsias que subjazem essa formação. Na sessão dedicada à apresentação, análise e discussão dos dados, são detalhados os seguintes aspectos: a metodologia de seleção dos ingressantes, o público-alvo pretendido e público-alvo alcançado, a estrutura curricular, a teoria e a prática como elementos intercambiáveis para a práxis tradutória e interpretativa na formação profissional de TILSP. O artigo conclui com as reflexões finais do autor que pondera sobre a necessidade de aprimoramentos, para que a extensão universitária se consolide como uma das modalidades de formação de TILSP.

\section{A extensão universitária COMO MODALIDADE DE FORMAÇÃO DE TILSP EM NÍVEL MÉDIO}

A legalização da profissionalização de TILSP no Brasil é recente. Antes da promulgação da lei $\mathrm{n}^{\circ} 12.319 \mathrm{em}$ de $1^{\circ}$ de setembro de 2010, lei que regulamenta a profissão do Tradutor e Intérprete de Libras, não havia delimitações sobre como deveria ocorrer a formação desse profissional. Lacerda (2012) ao comentar sobre esse período pregresso à lei, explica que a formação do Intérprete de Língua de Sinais no Brasil dava-se de maneira informal, "pela convivência com a comunidade surda, em organizações religiosas mais frequentemente, sem que uma formação melhor organizada [fosse] frequente" (LACERDA, 2012, p. 273).

Embora, no ano de 2008, a Universidade Federal de Santa Catarina (UFSC) tenha começado, pela primeira vez no Brasil, a ofertar um curso de Letras Libras em nível de bacharelado, com o propósito de formar TILSP em nível de graduação, a lei $\mathrm{n}^{\circ}$ $12.319 / 2010$ trata da formação desse profissional apenas em nível médio. A referida lei dá os seguintes direcionamentos:

Art. 4ㅇ A formação profissional do tradutor e intérprete de Libras - Língua Portuguesa, em nível médio, deve ser realizada por meio de:

I - cursos de educação profissional reconhecidos pelo Sistema que os credenciou;

II - cursos de extensão universitária; e

III - cursos de formação continuada promovidos por instituições de ensino superior e instituições credenciadas por Secretarias de Educação. (BRASIL, 2010a, grifos nossos).

$\mathrm{O}$ destaque nos termos "em nivel médio" e "cursos de extensão universitária”, no excerto da lei supracitada, são propositais, pois a proposta original do projeto de lei, no artigo $3^{\circ}$ que fora vetado, pautava como requisito para o exercício da profissão de tradutor e intérprete de Libras a habilitação em curso superior em tradução e interpretação, com habilitação em LibrasLíngua Portuguesa.

A lei em discussão aponta para a demanda por formação de TILSP em nível médio no país, sendo a extensão universitária definida como uma das modalidades em que essa formação pode, a partir de então, ser ministrada. Ao passo que a exigência da formação apenas em nível médio é positiva, no sentido de ampliar as possibilidades de ingresso de mais pessoas nesse campo profissional carente, pode, por outro lado, ter o efeito negativo de facilitar o 


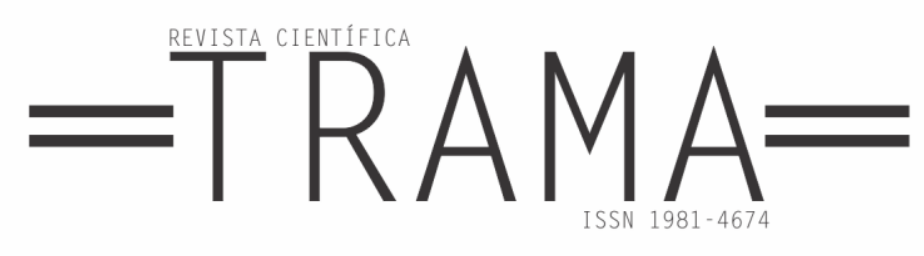

surgimento de formações de TILSP, nesse nível de ensino, sem mecanismos de controle de qualidade.

Um aspecto lacunar, da lei aqui discutida, por exemplo, é o não estabelecimento de uma carga horária mínima aceitável para uma formação via extensão universitária e a indefinição de uma base curricular comum para esses cursos. Lacunas desse tipo, podem favorecer a oferta de formações epidérmicas em seus aspectos teóricos e práticos. Nesse sentir, Santos (2006, p. 87) pontua que "um curso de 80 ou 120 horas é questionável, de forma geral, na formação de qualquer intérprete, uma vez que não dá conta da formação necessária para esses profissionais". Santos prossegue esclarecendo (2006, p. 88) que essa questão merece atenção, "pois é desses cursos que saem os profissionais com as noções mínimas a respeito do que é ser intérprete e quais são as habilidades necessárias para tal função".

Ainda que a lei $\mathrm{n}^{\circ} 12.319 / 2010$ não apresente a formação em nível superior como requisito para atuação profissional de TILSP, Albres (2012, p. 16, grifo no original) comenta que "a formação em Libras em nível de pós-graduação Lato Sensu vem crescendo no Brasil, mais que nos outros níveis". Em um de seus estudos, Albres (2010) analisa três projetos de cursos de pós-graduações em Libras, ofertados por Instituições de Ensino Superior privadas do estado de São Paulo, que visam a formação de TILSP, e aponta várias inconsistências nos projetos. Em uma de suas críticas acerca da carga horária desses cursos, Albres (2010, p. 5) afirma que "[...] a formação de intérpretes leva anos e a inscrição de iniciantes na língua em curso de 360 horas não os confere uma competência profissional, mas os confere um título acadêmico".

Em que pese os argumentos plausíveis de Albres (2010) e Santos (2006), não se pode negar a demanda por profissionalização de TILSP em nível médio. Os fatores de debilidade nas formações, apontados por ambas, são válidos, entretanto não podem ser os únicos determinantes a serem considerados quando as condições ideias nem sempre estão disponíveis. É preciso ter clareza de que cada situação exige enfrentamentos singulares, por vezes controversos e desafiadores, pois a distribuição de saberes e oportunidades não são equânimes nas regiões brasileiras. Além disso, há um estigma muito forte sobre as atividades extensionistas, como se a extensão fosse, nas palavras de Brandão (2016, p. 13), “[...] a quase irmã caçula e pobre da 'trindade universitária"”.

Para Souza (2016, p. 47-48), entretanto, as atividades extensionistas tem um outro caráter, pois

A extensão universitária representa a possibilidade de instrumentalizar, dialeticamente, a participação popular no processo de construção do conhecimento científico-acadêmico e em sua consequente influência na transformação da realidade concreta.

[...] A participação popular, em termos igualitários, é essencial no desenvolvimento de ações extensionistas que abram as portas das universidades para a sociedade (SOUZA, 2016, p. 47-48).

É com esse entendimento, de que a universidade não apenas pode, mas deve abrir suas portas para a sociedade e, através da participação popular, produzir conhecimento que vise a transformação de uma realidade concreta, que a formação de TILSP por meio de cursos de extensão universitária pode ser uma estratégia, válida e exequível, de transformação social. Em situações similares às vivenciadas no Piemonte Norte do Itapicuru, em que a carência de formação profissional de TILSP cede espaço ao improviso, a universidade não pode se furtar do seu papel de instituição formadora por excelência. 


\section{$=$ TRAMA $=$}

\section{Apresentando o curso de EXTENSÃO EM FORMAÇÃO DE TRADUTORES E INTÉRPRETES DE LIBRAS EM NÍVEL MÉDIO - FORMATILSP ${ }^{4}$}

O Formatilsp teve como objetivo central propiciar aos TILSP que já atuavam de forma empírica, no Território do Piemonte Norte do Itapicuru, uma formação que desse subsídios teóricos e práticos que robustecessem as competências tradutórias e interpretativas desses sujeitos. Ofertou-se 30 vagas para a composição de turma única, tendo como público-alvo falantes bilíngues da Libras/Língua Portuguesa, com escolaridade de nível médio, que já atuavam, ou que pretendiam atuar, como TILSP. A seleção dos candidatos seguiu as seguintes etapas: comprovação de escolaridade em nível médio (obrigatório); comprovação de experiência profissional como tradutor e intérprete educacional (opcional, valendo até 20 pontos); carta de intenções (obrigatória, valendo até 40 pontos); e entrevista (obrigatória, valendo até 40 pontos). Os candidatos que atingissem, no mínimo, 50 pontos estariam classificados.

As entrevistas foram filmadas e seguiram o mesmo roteiro para todos os candidatos, contendo 4 perguntas padronizadas. $\mathrm{Na}$ segunda pergunta, o candidato era interrogado sobre como avaliava seu próprio conhecimento da Libras, dadas três categorias: pouco, regular ou excelente. A partir da resposta, o candidato sorteava um vídeo em Libras dentre os vídeos previamente selecionados pela comissão avaliadora para comporem as três categorias apresentadas - e, após exibição única do vídeo, deveria dizer o que entendera da sinalização. A terceira pergunta era feita em Libras e o entrevistado deveria respondê-la em Libras.

\footnotetext{
4 Formatilsp foi o acrônimo usado pelo idealizador do projeto para se referir ao Curso de Extensão em Formação de Tradutores e Intérpretes de Libras/Língua Portuguesa, em nível médio, ofertado pela Univasf.

5 Por questões éticas, todos os dados apresentados neste artigo foram cedidos pelos
}

O principal objetivo da entrevista era verificar o conhecimento da Libras dos candidatos e, assim, direcionar as disciplinas de acordo com as necessidades da prospectiva turma. Nenhum dos entrevistados, quando interrogados sobre como avaliavam seu conhecimento da Libras, disseram ter um conhecimento excelente. Trinta e oito entrevistados se declararam com pouco conhecimento da Libras, 25 disseram ter um conhecimento regular e 3 candidatos afirmaram não ter conhecimento algum. Sete candidatos não compareceram à entrevista.

\section{Do Perfil PRETENDIDO AO PERFIL DO EGRESSO}

Inscreveram-se para participar da seleção um total de 73 candidatos, sendo 65 mulheres e 8 homens. A análise do conteúdo das cartas de intenções e, também, das entrevistas, sugere que a maioria dos candidatos não estava interessada em ser TILSP, senão em aprender a Libras para melhorar sua comunicação com pessoas surdas na família, na escola e/ou no trabalho. Apresenta-se a seguir, com recuo diferenciado das demais citações deste artigo, um dos trechos da carta de intenções de uma candidata que ilustra outros achados semelhantes nas demais cartas:

A língua de sinais serve de base para o aprendizado de todos os conteúdos escolares, em todas as disciplinas. Dessa forma, a Libras permite o meu crescimento profissional na área da educação para surdos, facilitando o desenvolvimento de atividades no meu cotidiano profissional e aprender uma nova língua me permite desenvolver uma nova maneira de comunicação, consequentemente amplia minha capacidade expressiva. (Colaboradora 1 - Candidata ao Formatilsp ${ }^{5}, 2015$ )

colaboradores dessa pesquisa mediante prévia autorização. Objetivando preservar suas identidades, cada sujeito será tratado como Colaborador(a), seguido de um número em algarismo arábico. 


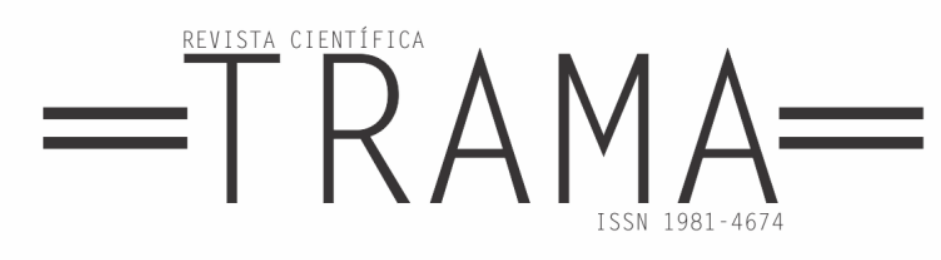

É possível verificar no trecho acima que, mesmo o edital ${ }^{6}$ de seleção esclarecendo que o objetivo do curso era formar TILSP, a candidata tinha interesse em "aprender uma nova língua" e "desenvolver uma nova maneira de comunicação". Falas semelhantes a essas foram percebidas na maioria das cartas de intenções avaliadas e nas respostas dadas pelos entrevistados.

Esta análise corrobora com as palavras de Santos (2006, p. 88) quando ela argumenta que "muitas pessoas que são bilíngües [sic] confundem os cursos de formação para intérpretes com o curso de LIBRAS avançado e não desejam se tornar ILS [Intérpretes de Língua de Sinais], mas sim aperfeiçoar a LS [Língua de Sinais]”.

O quadro, a seguir, apresenta o perfil dos candidatos que foram aprovados no processo seletivo:

Quadro 1 - Perfil dos candidatos aprovados na seleção do Formatilsp

\begin{tabular}{|l|c|}
\hline \multicolumn{1}{|c|}{ DESCRIÇÃO DO PERFIL } & QUANTIDADE \\
\hline Mulheres selecionadas & 28 \\
\hline Homens selecionados & 03 \\
\hline Autodeclarados com pouco conhecimento da Libras selecionados & 15 \\
\hline Autodeclarados com conhecimento regular da Libras selecionados & 15 \\
\hline Autodeclarados com conhecimento excelente da Libras selecionados & 00 \\
\hline Autodeclarados sem conhecimento algum da Libras selecionados & 01 \\
\hline Selecionados com escolaridade de nível superior completo & 16 \\
\hline Selecionados com escolaridade de nível superior incompleto & 07 \\
\hline Selecionados com escolaridade de nível médio & 08 \\
\hline
\end{tabular}

Fonte: Elaborado pelo autor

Os dados do quadro acima mostram que a turma ficou mista, tendo 15 alunos com conhecimento regular, $15 \mathrm{com}$ pouco conhecimento e 1 sem conhecimento algum de Libras. Essa composição não era a idealizada pelos professores formadores, pois o curso foi estruturado para acolher pessoas com conhecimento regular (intermediário) da Libras. Esta incompatibilidade, entre o perfil ideal de candidatos pretendidos e o perfil real selecionado, refletiu-se no resultado da formação, pois a maioria dos ingressantes com pouco conhecimento da Libras não a concluíram.

Somente 14 alunos permaneceram até o final do curso; 11 desistiram e 6 foram reprovados no percurso formativo. $\mathrm{O}$ curso

\footnotetext{
${ }^{6}$ Para acessar e consultar o edital de seleção acesse:

<https://www.sistemas.univasf.edu.br/ps/>. $\mathrm{Na}$ aba "Situação do Processo Seletivo" selecione a
}

foi direcionado para pessoas com nível médio de escolaridade, contudo a maioria dos ingressantes e concluintes tinham nível superior completo. Uma das alunas que, desde o início da seleção, autodeclarou-se sem conhecimento algum de Libras concluiu com êxito a formação, sendo este um dado curioso e sugestivo de maior escrutínio científico. Nesse sentido, vale ressaltar que, mesmo não sendo o ideal, há cursos de formação de intérpretes de língua de sinais em alguns países europeus como, "França, Dinamarca e Alemanha", por exemplo, que também não exigem, dos ingressantes, domínio da língua de sinais (QUADROS, 2004, p. 52).

O quadro sinóptico, a seguir, apresenta o perfil do egresso formado pelo Formatilsp:

opção Encerrados>Formação de Tradutores e Intérpretes de Libras/Português $>$ Edital de Abertura. 


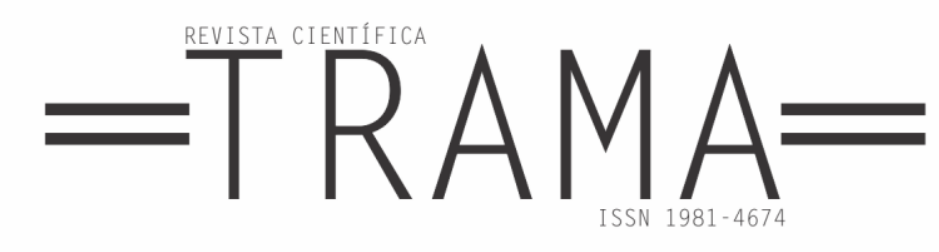

Quadro 2 - Perfil do egresso formado pelo Formatilsp

\begin{tabular}{|l|c|}
\hline \multicolumn{1}{|c|}{ DESCRIÇÃO DA CATEGORIA } & QUANTIDADE \\
\hline Mulheres concluintes & 12 \\
\hline Homens concluintes & 02 \\
\hline Autodeclarados com pouco conhecimento da Libras concluintes & 04 \\
\hline Autodeclarados com conhecimento regular da Libras concluintes & 09 \\
\hline Autodeclarados com conhecimento excelente da Libras concluintes & 00 \\
\hline Autodeclarados sem conhecimento algum da Libras concluintes & 01 \\
\hline Alunos com escolaridade de nível superior completo concluintes & 08 \\
\hline Alunos com escolaridade de nível superior incompleto concluintes & 04 \\
\hline Alunos com escolaridade de nível médio concluintes & 02 \\
\hline Alunos desligados do curso por desistência & 11 \\
\hline Alunos desligados do curso por reprovação em alguma disciplina & 06 \\
\hline Total de alunos selecionados e convocados & 31 \\
\hline Total de alunos desligados & 17 \\
\hline Total de alunos formados & 14 \\
\hline
\end{tabular}

Fonte: Elaborado pelo autor

Os desligamentos motivados por desistência superaram àqueles por reprovação. $\mathrm{O}$ fato de ser turma única acabou sacrificando a formação dos alunos reprovados que, se tivessem oportunidade de reingressar em outra turma, poderiam retomar ao curso. Ademais, se o projeto inicial fosse pensado num público de alunos com pouco ou nenhum conhecimento de Libras a matriz curricular incluiria disciplinas de Compreensão e Produção de Libras, visando o nivelamento desses alunos em relação aos demais, e Estágio Supervisionado. É muito provável que essas adequações curriculares resultassem em maior aproveitamento dos discentes sem um histórico de vivência como TILSP.

\section{O currículo e os aspectos METODOLÓGICOS DO FORMATILSP}

Quadro 3 - Matriz curricular definitiva do Formatilsp

\begin{tabular}{|c|l|}
\hline COMPONENTE CURRICULAR & \multicolumn{1}{c|}{ EMENTA DO COMPONENTE CURRICULAR } \\
\hline Libras I - 40 Horas & $\begin{array}{l}\text { Introdução à Língua de Sinais. Mitos em relação à Língua de Sinais. } \\
\text { Propriedades das Línguas Humanas. As expressões faciais e seus aspectos }\end{array}$ \\
\hline
\end{tabular}

A proposta inicial do Formatilsp previa uma formação de 800 horas com 20 disciplinas. Porém, por falta de dotação orçamentária para contratação de docentes formadores, o projeto foi modificado. Com a colaboração de instituições parceiras foi possível adicionar dois professores formadores ${ }^{7}$ ao corpo docente do projeto que, juntamente com o coordenador do curso, formou a equipe de professores. $\mathrm{O}$ projeto de formação redesenhado passou a ter 12 disciplinas de 40 horas cada. A formação, nesse novo molde, teria a duração de 1 ano e carga horária total de 480 horas. O projeto final ${ }^{8}$, após modificações, foi apreciado e aprovado pela câmara de extensão da Univasf.

Abaixo apresenta-se a matriz curricular definitiva do Formatilsp e suas respectivas ementas:

\footnotetext{
${ }^{7}$ O Prof. Esp. Enos Figueredo de Freitas, então servidor do Instituto Federal de Educação, Ciência e Tecnologia Baiano (IF Baiano) e a Prof ${ }^{a}$ Esp. Enildes da Cruz Menezes de Freitas, então servidora da Prefeitura Municipal de Senhor do Bonfim, de forma profissional e colaborativa, atuaram intensamente como professores formadores do Formatilsp. A esses
}

docentes parceiros e às suas respectivas instituições de atuação as mais sinceras e cordiais expressões de gratidão e estima.

8 A íntegra do projeto está disponível em: $<$ http://proex.univasf.edu.br/wp-

content/uploads/Forma\%C3\%A7\%C3\%A3o-deTradutores-e-It\%C3\%A9rpretes-de-Libras.pdf> 


\section{$=$ TRAMA $=$}

\begin{tabular}{|c|c|}
\hline & $\begin{array}{l}\text { afetivos e gramaticais. Aspectos fonológicos e morfológicos da Libras. } \\
\text { Letramento em Libras. }\end{array}$ \\
\hline Estudos da Tradução I - 40 Horas & $\begin{array}{l}\text { Introdução aos estudos da tradução. Representações Sociais do Tradutor e } \\
\text { Intérprete. Tipologias tradutórias e interpretativas. Questões de fidelidade } \\
\text { na tradução. O processo tradutório e estratégias de tradução. Oficina de } \\
\text { Tradução da Libras/Português/Libras. }\end{array}$ \\
\hline Libras II - 40 Horas & $\begin{array}{l}\text { Sintaxe da Libras: construções de frases e estrutura das sentenças. } \\
\text { Aspectos biológicos e socioantropológicos da surdez. História da educação } \\
\text { de surdos. Letramento em Libras. }\end{array}$ \\
\hline Estudos da Tradução II - 40 Horas & $\begin{array}{l}\text { Esforços envolvidos no ato interpretativo. Estratégias de tradução } \\
\text { aplicáveis à interpretação. Tradução mediada por ferramentas de } \\
\text { tecnologia computacional. Aspectos funcionais da linguagem e do discurso } \\
\text { na tradução. Oficina de Tradução da Libras/Português/Libras. }\end{array}$ \\
\hline Libras III - 40 Horas & $\begin{array}{l}\text { Os sinais classificadores, suas tipologias e usos. Os espaços de sinalização. } \\
\text { Leitura e produção de textos em Libras. }\end{array}$ \\
\hline $\begin{array}{l}\text { Laboratório de Tradução e } \\
\text { Interpretação da Libras/Língua } \\
\text { Portuguesa I - } 40 \text { Horas }\end{array}$ & $\begin{array}{l}\text { Uso de textos e videotextos diversificados para a prática da Interpretação } \\
\text { Consecutiva, Simultânea e tradução da Libras para a Língua Portuguesa e } \\
\text { vice-versa. Compreensão do método GISH de gerenciamento de } \\
\text { informação e sua aplicabilidade ao processo interpretativo. }\end{array}$ \\
\hline Escrita de Sinais I - 40 Horas & $\begin{array}{l}\text { Introdução à escrita de sinais. O sistema Sign Writing, suas regras } \\
\text { ortográficas básicas e as simbologias que o compõe. Escrita de sinais no } \\
\text { computador mediada pelo } S W \text {-Edit. }\end{array}$ \\
\hline $\begin{array}{l}\text { Laboratório de Tradução e } \\
\text { Interpretação da Libras/Língua } \\
\text { Portuguesa II - } 40 \text { Horas }\end{array}$ & $\begin{array}{l}\text { Uso videotextos diversificados para a prática da Interpretação Consecutiva } \\
\text { e Simultânea da Libras/Língua Portuguesa/Libras; e de textos para a } \\
\text { prática da tradução da Língua Portuguesa para a Libras. Compreensão do } \\
\text { conceito de "footing" (alinhamento) e de "enquadre de eventos" para a } \\
\text { práxis interpretativa no espaço pedagógico. }\end{array}$ \\
\hline Escrita de Sinais II - 40 Horas & $\begin{array}{l}\text { Leitura e produção de textos em Escrita Sinais. Transcrição de videotextos } \\
\text { em Libras para a Escrita de Sinais. Tradução de Textos em Escrita de } \\
\text { Sinais para a Língua Portuguesa. Introdução ao uso do Sign Puddle. }\end{array}$ \\
\hline $\begin{array}{l}\text { Laboratório de Tradução e } \\
\text { Interpretação da Libras/Língua } \\
\text { Portuguesa III - } 40 \text { Horas }\end{array}$ & $\begin{array}{l}\text { Uso videotextos diversificados para a prática da Interpretação Consecutiva } \\
\text { e Simultânea da Libras/Língua Portuguesa/Libras. Interpretação para a } \\
\text { mídia e tradução/legendagem. Aspectos técnicos e éticos da interpretação } \\
\text { jurídica/forense e médica/clínica. Intérprete religioso e as marcas das } \\
\text { crenças do profissional da tradução presentes no discurso escrito e falado. }\end{array}$ \\
\hline $\begin{array}{l}\text { Tradução e Interpretação da Libras - } \\
40 \text { Horas }\end{array}$ & $\begin{array}{l}\text { Ética, moral e seus pressupostos filosóficos. Ética profissional do tradutor } \\
\text { e intérprete de Libras/Língua Portuguesa. A importância da ética entre os } \\
\text { pares de profissão. Avaliação da competência profissional do tradutor nos } \\
\text { exames admissionais. Conflitos éticos, posturas e atitudes questionáveis. }\end{array}$ \\
\hline $\begin{array}{l}\text { Laboratório de Tradução e } \\
\text { Interpretação da Libras/Língua } \\
\text { Portuguesa IV - } 40 \text { Horas }\end{array}$ & $\begin{array}{l}\text { Uso de videotextos diversificados para a prática da Interpretação } \\
\text { Consecutiva e Simultânea da Libras/Língua Portuguesa/Libras. Tradução } \\
\text { e interpretação de provas escolares e de concursos públicos. Interpretação } \\
\text { de conferência. Tradução de músicas para a Libras. }\end{array}$ \\
\hline
\end{tabular}

Fonte: Elaborado pelo autor

O curso foi totalmente presencial, com as aulas ministradas em Língua Portuguesa ou em Libras. A escolha pela língua de instrução dava-se pela característica da disciplina e pela metodologia adotada pelo professor. O principal objetivo de ter aulas ministradas em Libras era fornecer "insumo linguístico compreensível [comprehensible input]" (KRASHEN, 1982, p. 22) na segunda língua dos estudantes - a Libras.

Dividido em seis módulos bimestrais, o Formatilsp ofertava duas disciplinas por módulo na sequência em que aparecem elencadas no Quadro 3. Para avançar nos módulos formativos, os discentes deveriam atingir média igual ou superior a 6,0 (seis), em cada componente curricular, e ter frequentado a, no mínimo, $75 \%$ das aulas em cada disciplina. Os discentes que não atingiam a média estabelecida, realizavam um exame final e se, ainda assim, não lograssem êxito, eram reprovados e desligados do curso.

\section{TeOria e PRÁtica COMO ELEMENTOS INTERCAMBIÁVEIS}

Além do desafio de trabalhar com uma turma mista, no que se refere ao nível de 


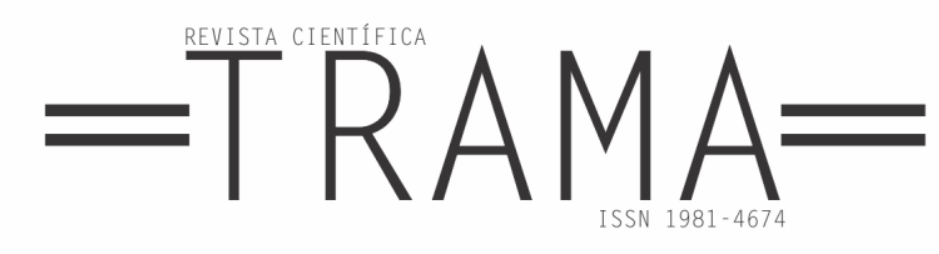

proficiência da Libras, delinear uma formação para além da "competência linguística" e da "competência referencial" (AUBERT, 1994 apud BARTHOLAMEI JUNIOR e VASCONCELOS, 2008, p. 15) foi um ponto nevrálgico do Formatilsp. Comentando sobre o desafio que se impõe à formação de TILSP, Albres (2012, p. 14) expressa-se nos seguintes termos:

Comprometida com a transformação da realidade, submergida pelo materialismo histórico dialético, valorizando a subjetividade e a singularidade de cada aluno (pesquisador-aprendiz), distancio-me do modelo de formação tecnicista procurando encaminhar a formação de intérpretes de Libras como pesquisadores comprometidos com a construção de conhecimento para sua área de atuação (ALBRES, 2012, p. 14).

Refutando o ideal tecnicista nas formações de TILSP, Albres (2012, p. 14) critica o caráter pragmático de alguns cursos e sugere que o melhor caminho seria uma formação acadêmica "de perfil clássico, com preparação teórico-cientifica. Uma formação consistente que permita desenvolver a reflexão sobre a prática, revendo e reelaborando o seu fazer". Este movimento, de reflexão da prática à luz de teorias, foi especialmente importante no Formatilsp, pois havia alunos que já atuavam como intérpretes sem nenhuma formação específica. Destarte, as disciplinas de Estudos da Tradução e os Laboratórios não eram apenas disciplinas práticas ou teóricas, mas práticas e teóricas.

O curso buscou iniciar os discentes no campo disciplinar dos Estudos da Tradução, apresentando a tradução e interpretação como um campo fértil para pesquisa e produção de conhecimento. Nesse intento, foram apresentados e explorados estudos teóricos clássicos, modernos e contemporâneos (CÍCERO [106 a. C - 43 a. C]; HORÁCIO [65 a. C -8 a. C]; DOLET [1509 - 1556]; DRYDEN [1631-1700]; TYTLER

[1747-1813];

9 Sinal identificador é uma alcunha que cada indivíduo recebe quando passa a fazer parte do cotidiano da comunidade surda. Esse sinal é
SCHLEIERMACHER [1768 - 1834]; JACKOBSON [1975]; RONAI, [1976]; ARROJO [1986]; KRINGS [1986]; AUBERT [1994]; GILE [1995]; PAGANO [2000]; BARBOSA [2004]; GUERINI [2008]; QUADROS [2004]; SOUZA [2006]; ALBRES e SANTIAGO [2012];) sobre tradução e interpretação tanto das línguas orais como das línguas de sinais.

Desde o início da formação, buscou-se desenvolver atividades práticas de tradução e interpretação, concebendo prática e teoria como elementos intercambiáveis e complementares na práxis tradutória e interpretativa. Para exemplificar, apresentase, nos próximos parágrafos, o primeiro exercício proposto à turma - a tradução do trecho de uma reportagem transcrito abaixo:

\begin{abstract}
Em retaliação ao PT e ao Planalto, que não asseguraram votos para enterrar seu processo de cassação, o presidente da Câmara dos Deputados, Eduardo Cunha (PMDB-RJ), anunciou às $18 \mathrm{~h} 38$ desta quarta-feira (2) a deflagração do principal pedido de impeachment contra Dilma Rousseff. (FOLHA DE SÃO PAULO, 2015)
\end{abstract}

Ao selecionar esse excerto da reportagem, o professor formador previa que os alunos se deparariam com pelo menos três problemas. Primeiro, como traduziriam para a Libras a linguagem conotativa "enterrar seu processo"; segundo, como descobririam o sinal identificador" usado para "Eduardo Cunha"; e terceiro, como resolveriam o problema terminológico da palavra "impeachment", que, à época, era pouco familiar ao público alvo da tradução - os surdos. As previsões se confirmaram e, a partir dos problemas que emergiam da atividade tradutória proposta, os alunos eram orientados a lançar mão das teorias de Gile (1995) - sobre ganhos e perdas de informação na tradução - e das estratégias de tradução propostas por Krings (1986).

No caso do termo "enterrar seu processo", dos 10 alunos que fizeram a tradução para a Libras e a registraram em

motivado e atribuído, na maioria dos casos, por alguma característica física saliente de cada pessoa. 


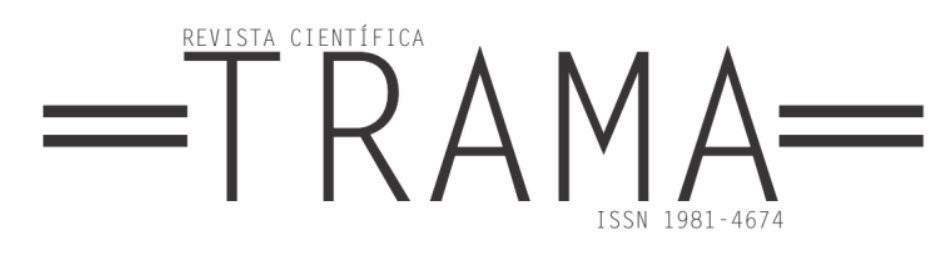

formato de vídeo, uma das discentes, Colaboradora 2, optou por uma tradução literal que transcrevo abaixo em SignWriting ${ }^{10}$ acompanhada da respectiva tradução em língua portuguesa:

Figura 2 - Transcrição da tradução literal da Colaboradora 2

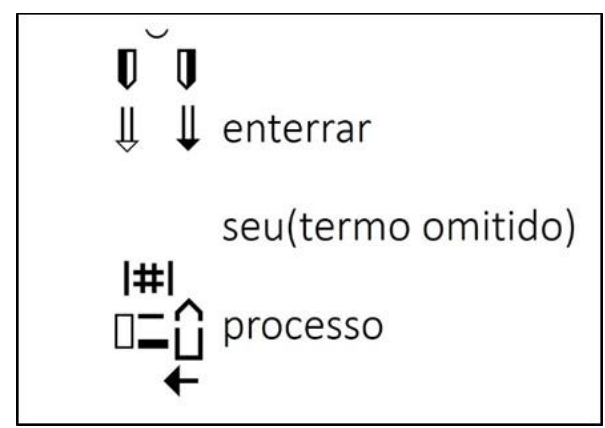

Fonte: elaborado pelo autor

O principal problema do sinal usado pela discente para tradução do termo "enterrar" é ป

que o sinal "enterrar" $\Downarrow \Downarrow$ transmite o sentido literal de sepultar, estritamente relacionado ao enterro de cadáver, não podendo ser semanticamente estendido ao contexto da reportagem. Uma outra discente, Colaboradora 3, apresentou uma alternativa para o termo "enterrar", presente no texto de partida, utilizando o sinal de "cancelar" no texto de chagada. A seguir, apresenta-se em SignWriting e com a respectiva tradução para língua portuguesa, o sinal utilizado pela Colaboradora 3:

\footnotetext{
${ }^{10}$ A leitura do SignWritng é feita em colunas de cima para baixo, começando da coluna da esquerda e seguindo para a coluna da direita. A opção pela transcrição em SignWriting, neste trabalho, visa preservar as identidades dos colaboradores e publicizar este sistema de escrita. Para um estudo detalhado do SignWriting
}

Figura 3 - Alternativa apresentada pela Colaboradora 3 para o termo "enterrar"

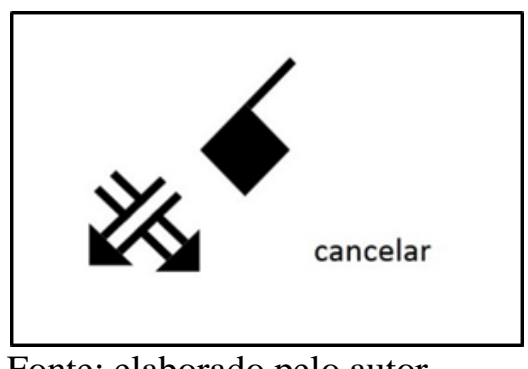

Fonte: elaborado pelo autor

Ao optar pelo uso do sinal "cancelar"

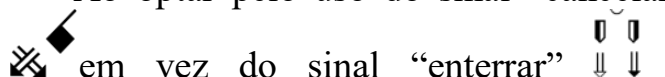
Colaboradora 3 lançou mão das estratégias tradutórias postuladas por Krings (1986 apud BARTHOLAMEI e VASCONCELOS, 2008, p. 38, itálicos dos autores), principalmente, da "estratégia de redução" que "consiste em desistir da linguagem marcada ou do caráter metafórico de um item do texto da língua fonte e substituí-lo por um equivalente nãomarcado ou não-metafórico."

Sobre o sinal identificador para "Eduardo Cunha", 7 discentes, valendo-se das estratégias de busca, sugeridas por Krings (1996), conseguiram encontrar o sinal identificador pesquisando na internet. Os demais fizeram apenas a transliteração do nome do parlamentar utilizando o alfabeto manual da Libras. Um dos maiores problemas das buscas por terminologias em Libras na internet, é a falta de um dicionário com banco de dados vasto, atualizado e que seja uma fonte confiável de informação. Embora muitos vídeos sejam disponibilizados na rede, nem sempre é possível checar a procedência e fidedignidade das informações disponibilizadas.

Por fim, o último item, o problema gerado pela terminologia "impeachment". Uma discente fez apenas a transliteração da palavra "impeachment" por meio da

queira consulta a tese: Aprendizagem de Escrita de Lingua de Sinais pelo Sistema Sign Writing: línguas de sinais no papel e no computador, de autoria de Marianne Rossi Stumpf, disponível em:

$<$ http://www.lume.ufrgs.br/bitstream/handle/101 83/5429/000515254.pdf?sequence=1>. 


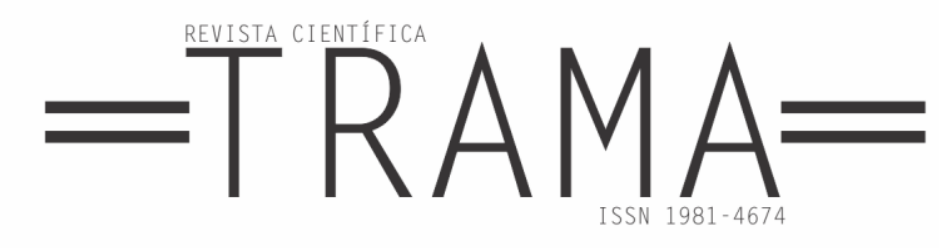

soletração, utilizando o alfabeto manual da Libras. Três discentes recorreram ao acréscimo de Informação Contextualizadora [Framing Information], conforme explicitação de Gile (2009, p. 57). Esses alunos, além de fazerem a transliteração para Libras da palavra "impeachment", acrescentaram, também, uma explicitação breve do termo. Uma das alunas, Colaboradora 4, fez a explicitação conforme transcrição abaixo:

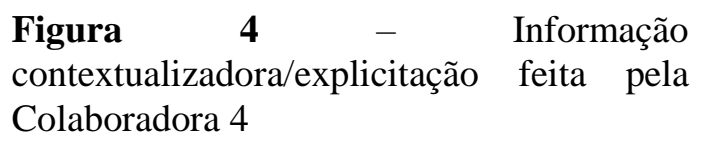

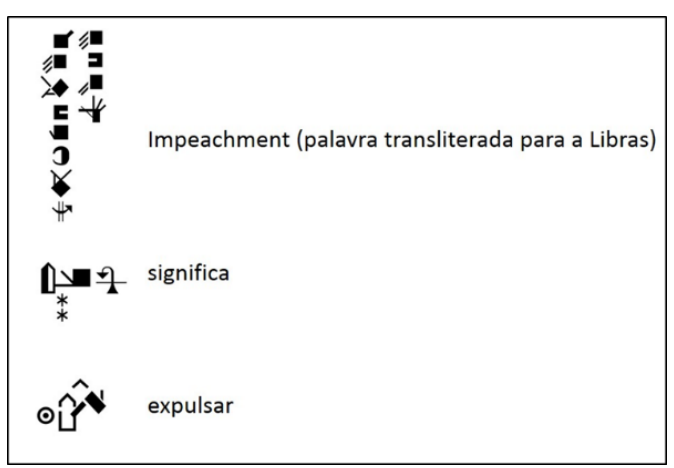

Fonte: elaborado pelo autor

Os outros seis alunos optaram por usar o sinal $\odot \hat{\mathcal{F}}$ " "expulsar" como termo equivalente à palavra "impeachment". Nesse caso, recorreram à estratégia de redução proposta por Krings (1996), eliminando a linguagem marcada, no caso a terminologia estrangeira, substituindo-a por um termo semanticamente aproximado. Foi nessa proposta dinâmica de intercambio teóricoprático que as atividades de tradução e interpretação se desenvolveram no Formatilsp.

\section{Considerações finais}

Certamente, como qualquer outra iniciativa embrionária, o Formatilsp é um projeto passível de críticas e aprimoramentos. Logo, este trabalho não intencionou mostrar um modelo ideal para formação de TILSP, mas apresentar a extensão universitária como uma modalidade viável para a formação desses profissionais em nível médio. Ademais, também buscou incitar o aprofundamento das discussões teóricas em torno da extensão universitária como modalidade de formação profissional de TILSP, em nível médio, e debater a urgente necessidade de ampliação do acesso e interiorização dos espaços formais para uma capacitação ética e humanizada dos mesmos.

Destarte, foram apontadas lacunas contidas na lei $\mathrm{n}^{\circ} 12.319 / 2010$, principalmente, quanto ao não estabelecimento de uma carga horária mínima e de uma base curricular comum às modalidades de formação de TILSP em nível médio, como os cursos de extensão universitária, por exemplo. No caso específico do Formatilsp, somam-se a esses fatores lacunares da lei, a escassez acentuada de recursos financeiros para o projeto e a carência de docentes formadores, que resultaram na reelaboração de um currículo menos robusto.

Dos 14 discentes formados pelo Formatilsp, apenas 4 não residiam na região do Piemonte Norte do Itapicuru. Ressalte-se que 10 intérpretes ainda não suprem à demanda local, mas já representam um ganho para uma região que, até a conclusão do curso, contava com apenas três. Cabe frisar que a quantidade de desistentes e reprovados impedidos de prosseguir o percurso formativo apontam para a necessidade de ampliação de oportunidades, aprimoramentos metodológicos, reestruturação curricular e pedagógica para a consolidação de um projeto que anseia suplantar o caráter experimental.

Almeja-se que este artigo e os relatos nele contidos tenham demonstrado que não se pode confundir extensão universitária com espaço de improviso acadêmico, pois essa modalidade de formação de TILSP precisa ser encorajada e difundida com muita responsabilidade. A carência de espaços formais para formação de TILSP, em nível médio, em algumas regiões menos favorecidas do Brasil, entre elas o semiárido baiano representado neste trabalho pelo Piemonte Norte do Itapicuru, corroboram para a adoção de alternativas menos burocráticas, mas, nem por isso, sem o 


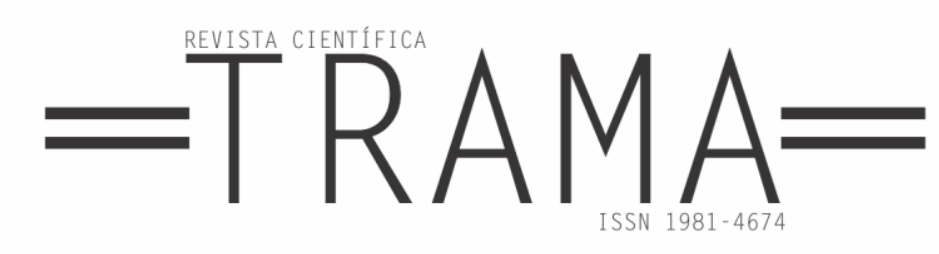

cuidado e o rigor acadêmico-científico tão necessários para sua implementação.

\section{R EFERÊNCIAS}

ALBRES, Neiva de Aquino. Processos de produção e legitimação de saberes para o currículo de pós em libras na formação de intérpretes. Para uma especialização? Congresso nacional de pesquisas em tradução e interpretação de Libras e Língua Portuguesa - Anais 2010. Disponível em: <http://www.congressotils.com.br/anais/ana is 2010/Neiva\%20de\%20Aquino\%20Albres. pdf>. Acesso em: 13 out. 2017

ALBRES, Neiva de Aquino. Formação acadêmico-científica do Tradutor/intérprete de Libras e português: o processo investigativo como objeto de conhecimento. In: Libras em estudo: tradução/interpretação. ALBRES, Neiva de Aquino; SANTIAGO, Vânia de Aquino Albres (Orgs.). São Paulo: FENEIS, 2012. p. 15-33.

BARTHOLAMEI JUNIOR, Lautenai Antonio; VASCONCELLOS, Maria Lúcia. Estudos da Tradução I. Universidade Federal de Santa Catarina. Florianópolis, 2008.

BRANDÃO, Carlos Rodrigues. Do começo dos anos sessenta para os anos de agora. In: Extensão universitária: metodologia e experiências. SOUZA, Murilo Mendonça Oliveira de; CARVALHO, Guido de Oliveira. Goiânia: Ed da PUC Goiás, 2016.

BRASIL. Perfil Territorial: Piemonte Norte do Itapicuru-BA. Brasília: Ministério do Desenvolvimento Agrário, 2015. Disponível em: <http://sit.mda.gov.br/download/caderno/ca derno_territorial_185_Piemonte\%20Norte $\% 20$ do\%20Itapicuru\%20-\%20BA.pdf $>$. Acesso em: 13 out. 2017

BRASIL. Lei $n^{\circ} 12.319$ de $1^{\circ}$ de setembro de 2010. Regulamenta a profissão do
Tradutor e Intérprete de Língua Brasileira de Sinais - Libras. Disponível em: <http://www.planalto.gov.br/ccivil_03/_Ato 2007-2010/2010/Lei/L12319.htm>.

Acesso em: 13 out. 2017

FOLHA DE SÃO PAULO. Eduardo Cunha acata pedido de impeachment contra Dilma Rousseff. São Paulo: 02/12/2015. Disponível em: <http://www1.folha.uol.com.br/poder/2015/ 12/1714133-cunha-deflara-processo-deimpeachment-contra-dlma.shtml>. Acesso em: 13 out. 2017

FREITAS, Enos Figueredo de. Educação de surdos: uma pesquisa sobre práticas inclusivas no Território do Piemonte Norte do Itapicuru. Revista de Educação do Vale do São Francisco - REVASF. Petrolina PE: vol. 3, n. 1, p. 44-60, ago. 2014.

FREITAS, Isaac Figueredo de. O tradutor e intérprete de LIBRAS: adequando a práxis tradutória à dinâmica do espaço pedagógico. Revista virtual de cultura surda. Petrópolis -RJ: Arara Azul, Ed. 12, p. 1-31, jan. 2014.

GILE, Daniel. Basic concepts and models for interpreter and translator training. Rev. ed. Amsterdam: John Benjamins, 2009.

KRASHEN, Stephen. Principles and practice in second language acquisition. California: University of Southern California, 1982.

LACERDA, Cristina Broglia Feitosa de. O Intérprete de Língua Brasileira de Sinais (ILS). In: Letramento, bilinguismo e educação de surdos. LODI, Ana Claudia Balieiro; MÉLO, Ana Dorziat Barbosa de; FERNANDES, Eulália (Orgs.). Porto Alegre: Mediação, 2012. p. 247-302.

QUADROS, Ronice Müller de. O tradutor e intérprete de língua brasileira de sinais e língua portuguesa. Brasília: MEC, 2004.

SANTOS, Silvana Aguiar dos. Intérpretes de língua brasileira de sinais: um estudo sobre as identidades. 2006. 198 fls. 


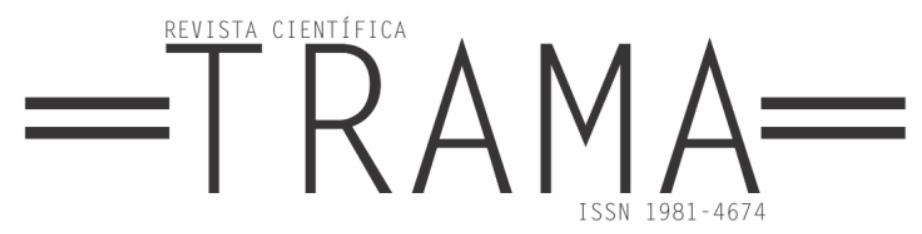

(Dissertação de mestrado em Educação) Florianópolis: UFSC, 2006.

SOUZA, Murilo Mendonça Oliveira de. Metodologias participativas em extensão universitária: o diagnóstico rural participativo (DRP). In: Extensão universitária: metodologia e experiências. SOUZA, Murilo Mendonça Oliveira de; CARVALHO, Guido de Oliveira. Goiânia: Ed da PUC Goiás, 2016. p. 47-66. 